\title{
O Uso do Laptop Educacional como Suporte ao Ensino de Química
}

\author{
Nayana Sousa de Oliveira ${ }^{1}$, Dayane de Sousa Carvalho ${ }^{2}$ \\ ${ }^{1}$ EEF Angélica Nogueira \\ ${ }^{2}$ Secretaria da Educação Básica (SEDUC-Ce) \\ nayanna_oliveira@yahoo.com.br, dayanels@yahoo.com.br
}

\begin{abstract}
: this paper conducted a study on the use of digital technologies in the development of chemistry teaching in a school which was participating in the project "Um computador por aluno" (UCA) (One Computer per Student). The use of a mobile device, such as the educational laptop in the classroom, requires that teachers use instructional strategies to encourage the participation of students in order to make the understand of educational contents more accessible students. In order to collect data, questionnaires to students and teachers were applied. The results bring reflections on the motivation of students and some factors that make it difficult to use more of that tool in the classroom .
\end{abstract}

Resumo: o presente trabalho realizou um estudo sobre o uso das tecnologias digitais no desenvolvimento do ensino de Química, no contexto de uma escola contemplada pelo projeto Um Computador por Aluno (UCA). A utilização de um dispositivo móvel, como o laptop educacional em sala de aula requer que professores utilizem estratégias didáticas capazes de incentivar a participação dos alunos a fim de tornar os conteúdos escolares mais acessíveis ao entendimento dos alunos. Para coletar os dados, foram aplicados questionários com alunos e professores. Os resultados obtidos trazem reflexões acerca da motivação dos estudantes e de alguns fatores que dificultam a utilização efetiva deste instrumento em sala de aula.

\section{Introdução}

O presente estudo teve como foco o Projeto Um Computador por Aluno (UCA). Tratase de um estudo acerca do ensino de Química com uso de laptops educacionais. Atualmente é difícil abordar o tema da educação sem falar das Tecnologias da Informação e Comunicação (TIC), que evoluem constantemente e estão, cada vez mais, presentes no mercado globalizado e nas práticas educativas.

Warschauer (2006) ressalta que para integração das TIC aos diversos setores são necessários projetos de inclusão. Desta forma será possível ampliar as oportunidade de acesso ao maior número de pessoas, requisito relevante ao atual momento histórico. No 
âmbito da escola é necessário incentivar o manuseio e o domínio dos equipamentos tecnológicos, de uma forma crítica e com concepção didática clara. É nesse contexto que surgiu o Projeto Um Computador por Aluno (UCA) tendo como objetivo a inclusão digital nas escolas, além de dar suporte às atividades docentes em sala de aula.

A presença de computadores na educação não é suficiente para promover as melhorias esperadas, é necessário aulas planejadas com estratégias, métodos e técnicas de ensino inovadores para se ter um aprendizado mais substancial e resultados mais satisfatórios. A chegada do laptop em sala de aula parte deste pressuposto.

Neste estudo, os laptops são utilizados em sala de aula como suporte ao ensino de Química, considerando que a utilização da informática no contexto escolar deve ir além do que é feito através do ensino tradicional, de forma a facilitar o entendimento dos conteúdos e tornar o aluno mais motivado e interessado em aprender.

Os conhecimentos específicos da disciplina Química no Ensino Médio apresentam um considerável grau de complexidade para ensinar e aprender, sendo necessários métodos práticos para a realização das aulas a fim de tornar os conteúdos disciplinares mais acessíveis ao entendimento dos alunos. Desta forma, as aulas ministradas somente com quadro e pincel não são compatíveis com a complexidade e grau de abstração requerida para a compreensão dos conceitos desta importante área do saber.

Nessa perspectiva foram analisados alguns métodos educacionais tendo como suporte o uso do laptop educacional presente em uma escola contemplada pelo projeto UCA, com o objetivo de responder às questões centrais deste trabalho, a saber:

$\checkmark$ Quais as possíveis contribuições do uso do laptop educacional nas aulas de Química no Ensino Médio?

$\checkmark$ Os professores incluem os equipamentos nos planejamentos mensais?

$\checkmark$ Quais as percepções dos estudantes acerca do uso dos laptops nas aulas de Química?

As disciplinas de ciências exatas exigem domínio de competências específicas. A complexidade no ato de ensinar e de aprender requer uma metodologia diferenciada que possa despertar ao aluno a curiosidade de adquirir conhecimentos essenciais promovendo interesse de conhecimentos da disciplina. No ensino médio a disciplina de Química requer estratégias que associem os conteúdos conceituais à situações do cotidiano. Ainda assim, existem alguns alunos que sentem dificuldades de aprendizagem e assim não mostram interesse no conteúdo ou na disciplina.

De acordo com os Parâmetros Curriculares Nacionais (PCNs) a inclusão de tecnologia no campo educacional deve propiciar como um complemento para o professor, ou até mesmo para auxiliar na metodologia em sala de aula, ou seja, "a tecnologia deve servir para enriquecer o ambiente educacional, propiciando a construção de conhecimentos por meio de uma atuação ativa, crítica e criativa por parte de alunos e professores. (BRASIL,1998, p.125)".

\section{Método}

Para desenvolver este estudo de natureza exploratória, conforme Gil (1991), que teve como objetivo identificar os problemas apresentados e assim construir hipóteses para a solução. Foram realizados alguns questionamentos relacionados ao ensino de Química, 
V Congresso Brasileiro de Informática na Educação (CBIE 2016)

Anais dos Workshops do V Congresso Brasileiro de Informática na Educação (CBIE 2016)

realizado de forma diferenciada através imersão do laptop educacional colocado à disposição dos alunos e professores em uma escola da zona rural da Cidade de QuixadáCe.

Aplicou-se um questionário com (15) questões a (10) professores de como os laptops auxiliam e se tem um bom desenvolvimento em sala de aula. E (15) questões a (50) alunos para saber se o Programa UCA está apresentando vantagens para o desenvolvimento de conhecimentos e para analisar se a presença do projeto UCA está contribuindo no ensino-aprendizagem do aluno.

Os dados referentes ao projeto Um Computador por Aluno (UCA) são transcritos em gráficos (FIGURAS) geradas no software Origin 7.0, apresentados em valores absolutos seguidos das respectivas discussões.

\section{Resultados}

A utilização de computadores na educação escolar necessita de aulas planejadas com estratégias metodológicas que favoreçam o alcance de resultados satisfatórios, sobretudo em áreas em que comumente os estudantes apresentam dificuldades de aprendizagem, como Química no Ensino Médio.

Este estudo reflete sobre utilização do laptop educacional em sala de aula como suporte ao ensino de Química. Considera-se que este instrumento tecnológico oferece contribuições a esta importante área do conhecimento, desde que consiga superar as técnicas mais frequentes no ensino tradicional, a saber: exposição oral e repetição de conteúdos.

Atualmente, o computador motiva o aluno e funciona como um suporte ao professor, buscando através dos diversos recursos disponíveis (vídeos, simulações, aplicativos, dentre outros) contribuir para melhorar a qualidade da educação desenvolvidas nas escolas.

No Brasil, tem-se um baixo índice de aprendizagem, e também evasão escolar que indicam falta de interesse de muitos. Logo, o programa UCA surgiu como contribuição da política de inclusão digital nas escolas, oferecendo oportunidades de estudar e o acesso tecnológico a populações carentes de escolaridade e inclusão social (TAVARES, 2013).

O projeto Um Computador por Aluno (UCA) permite que os gestores educacionais possam avaliar as atividades escolares vinculadas ao uso dos laptops dentro e fora da sala de aula, permitindo que o conhecimento se fortaleça consequentemente (CNPq, 2010).

O projeto UCA representa um desafio e também uma oportunidade de formação. Desafio, porque os professores além do treinamento que é feito, eles precisam se familiarizar e trabalhar em sala de aula com os laptops de maneira que os alunos se sintam motivados. Oportunidade de formação porque o programa contribui para desenvolver, no espaço escolar, iniciativas mais eficazes, preparando futuros profissionais (STRUCHINER, 2011; GIANNELLA 2011).

O foco do projeto UCA é pedagógico e teve como pressuposto a utilização do potencial das tecnologias digitais em sala de aula. O laptop educacional é trabalhado numa perspectiva didática e integrada ao currículo escolar. Seu uso teve objetivo auxiliar o ensino e, ao mesmo tempo, promover inclusão digital. 
V Congresso Brasileiro de Informática na Educação (CBIE 2016)

Anais dos Workshops do V Congresso Brasileiro de Informática na Educação (CBIE 2016)

Observa-se na figura 01 que $60 \%$ dos alunos gostam da disciplina de Química e $24 \%$ gostam pouco, mesmo sendo uma área que mostra complexidade. O elevado percentual de alunos que afirmaram gostar da disciplina é um indício consistente que a utilização do laptop educacional interfere na percepção positiva dos alunos em relação à disciplina Química, que por sua complexidade, desperta nos estudantes, certa rejeição.

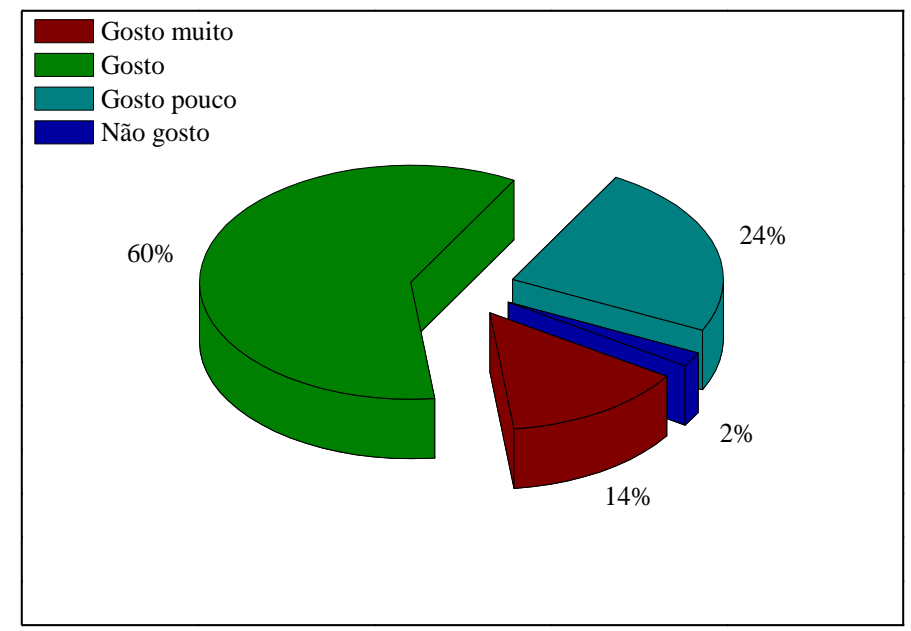

FIGURA 01. Alunos que gostam da disciplina de Química.

A figura 02 mostra que $30 \%$ dos alunos se sentem muito motivados nas aulas de Química com a utilização dos laptops e $40 \%$ apenas motivado. O Programa UCA veio para as escolas com o intuito de desenvolver melhorias na educação, sendo um auxílio em sala de aula, proporcionando metodologias inovadoras que despertem interesse pela disciplina.

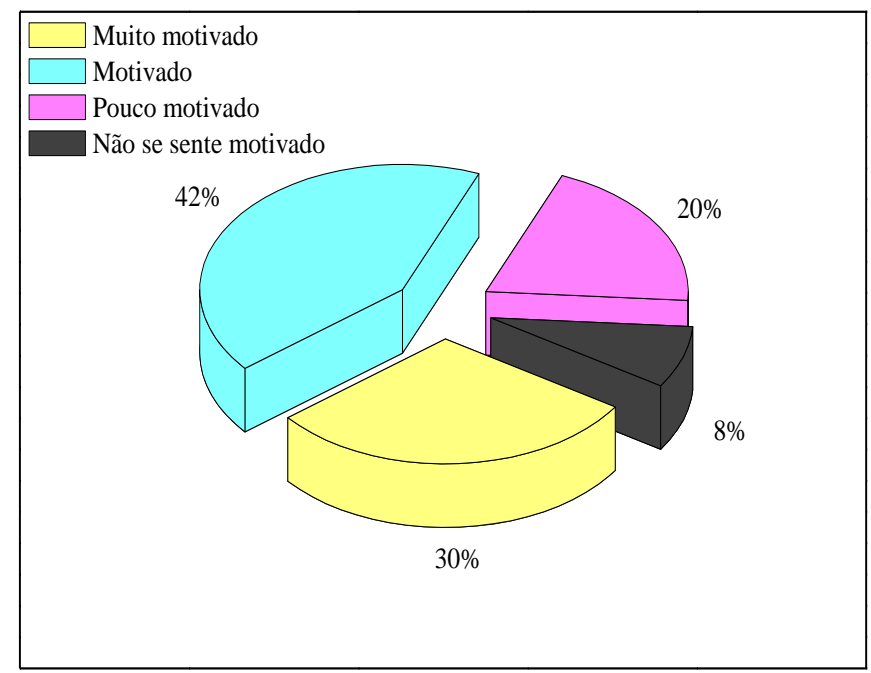

FIGURA 02. Motivação nas aulas de química com o uso dos laptops. 
V Congresso Brasileiro de Informática na Educação (CBIE 2016)

Anais dos Workshops do V Congresso Brasileiro de Informática na Educação (CBIE 2016)

A figura 03 mostra motivos que desfavorece o uso de laptops, percebe-se que $50 \%$ dos alunos consideram que a falta de interesse são dos próprios alunos e $26 \%$ responderam que o problema é o conteúdo apresentado, ou seja, o conteúdo não tem um bom desempenho com a utilização de laptops.

A falta de interação com o uso dos laptops deve acontecer pelo fato dos alunos não ter conhecimento para trabalhar com a máquina, pois atualmente ainda existem estudantes que não tem prática ao utilizar computadores ou até mesmo o motivo seja a timidez existente neles. Esse problema deve ser trabalhado, pois os projetos de informatização têm a finalidade de desenvolver a capacidade dos estudantes e desenvolver a inclusão digital inserida nas escolas.

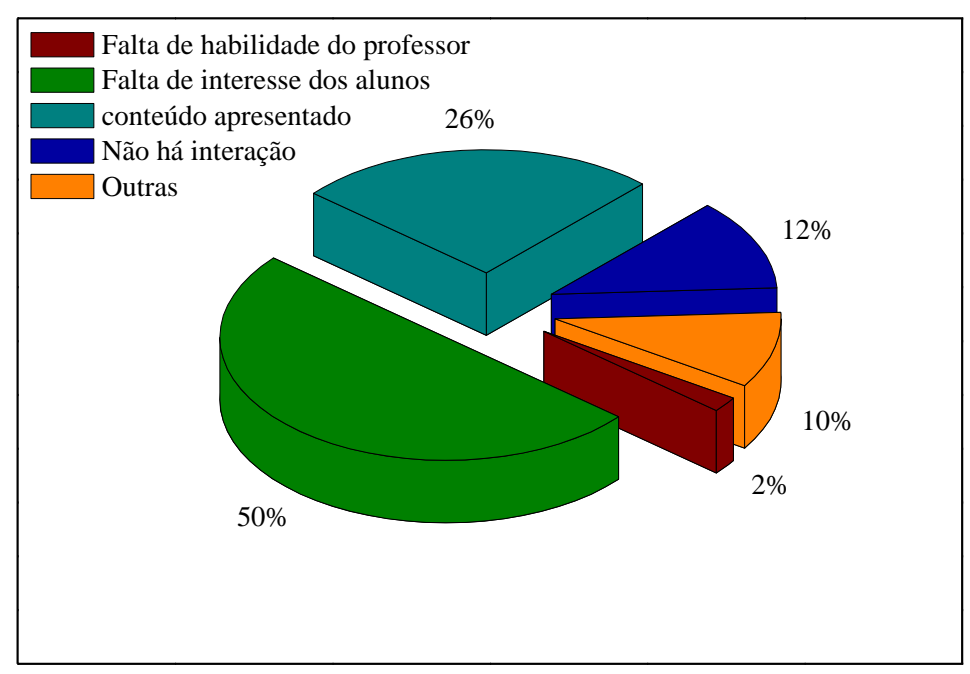

FIGURA 03. O que desfavorece o uso de laptops.

A figura 04 indica percentuais de professores que tem dificuldade ao utilizar os laptops em sala de aula e o percentual de alunos que tem interesse ao utilizá-lo.

A figura nos mostra que $70 \%$ dos professores consideram difícil a associação dos conteúdos com o uso de laptops e $10 \%$ afirmam terem dificuldades quanto ao seu uso. As dificuldades encontradas com associação dos conteúdos propostos devem ser trabalhadas frequentemente, para a resolução do problema, principalmente na área de ciências exatas que necessita de dinâmica e estratégias didáticas que facilitem o aprendizado.

De acordo com Aragão, (1995) para a realização do saber ensinar é importante se ter conhecimento do conteúdo específico e utilizar metodologias que permitam que os saberes disciplinares sejam apropriados pelos estudantes.

Os professores devem se apropriar criticamente dos instrumentos didáticos disponíveis na instituição escolar, de forma a proporcionar melhorias para educação, integrando-os ao ambiente de ensino-aprendizagem, produzindo uma interatividade e dinamismo na produção de conhecimento. 
V Congresso Brasileiro de Informática na Educação (CBIE 2016)

Anais dos Workshops do V Congresso Brasileiro de Informática na Educação (CBIE 2016)

Com os laptops alunos se sentem motivados e inovados com a presença de auxílios para o desenvolvimento de atividades escolar, afinal, eles têm preferência em atividades demonstrativas sejam aulas experimentais, uso de jogos pedagógicos ou com informatização.

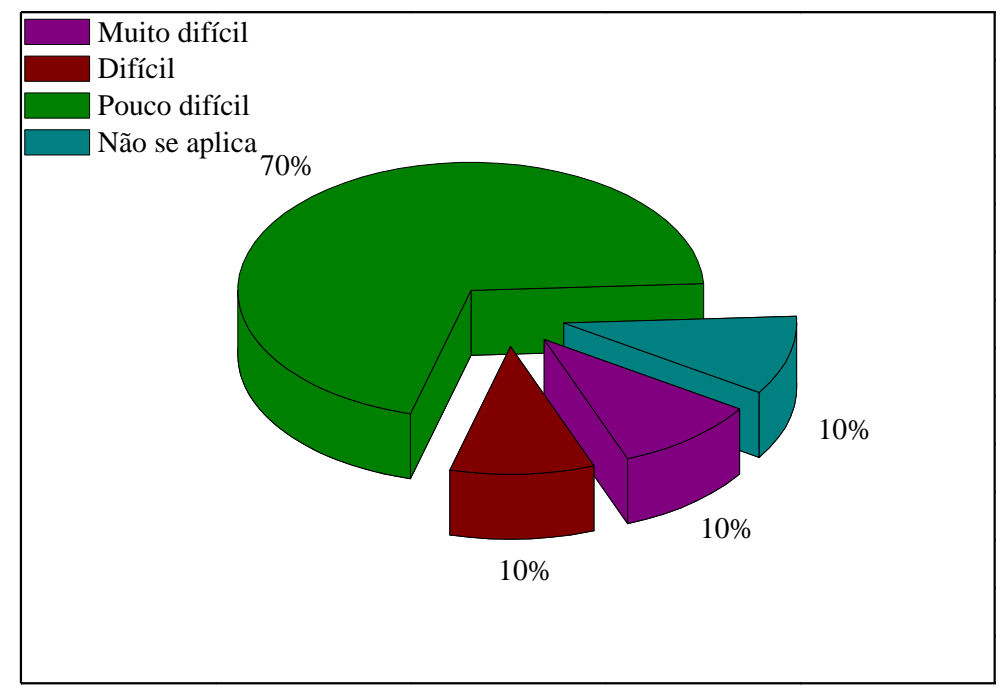

\section{FIGURA 04. Percentual de professores que apresentam as dificuldades dos alunos com a associação dos conteúdos com o uso de laptops.}

No item seguinte serão apresentadas as considerações finais deste trabalho.

\section{Conclusão}

Diante o perfil da escola analisada, podemos concluir que o acesso dos laptops na escola pública tem que estar mais presente nas aulas ministradas, a tecnologia é um auxílio inovador, mais a mudança só acontece se toda gestão escolar tiver o mesmo objetivo.

A inclusão digital é um indicador para o desempenho da melhoria da educação, pois ela está presente no campo escolar como um componente para a didática em sala de aula, tornando possível ao aluno o acesso a informação com os benefícios do governo, utilizando os laptops como auxílio para o crescimento de aprendizado.

As TIC são fundamentais para o desenvolvimento de trabalhos escolares, no ensino de Química os professores tentam trabalhar de forma metodológica para o desempenho de aprendizado dos alunos. Portanto, aborda-se que os alunos têm a necessidade de usar as TIC ainda mais com a presença do Programa UCA que veio para unificar a educação e a tecnologia para a realização e desenvolvimento de uma educação com um nível de habilidade e estimulação do uso de computadores.

O professor precisa fazer uma parceria entre a tecnologia e a Química direcionando as práticas educativas como uma forma de promover a inserção tecnológica integrando o aluno no mundo digital.

Inicialmente, professores tiveram situações desafiadoras com a presença do UCA, mais atualmente eles estão mais hábitos para a realização do trabalho em sala de 
V Congresso Brasileiro de Informática na Educação (CBIE 2016)

Anais dos Workshops do V Congresso Brasileiro de Informática na Educação (CBIE 2016)

aula, com a chegada do programa na escola os professores e toda gestão escolar passou por treinamentos, sendo cursos preparatórios para aprender como utilizar o sistema operacional do computador.

O presente estudo revela que o uso do laptop interfere de maneira positiva na motivação dos estudantes. Este fato pode ser considerado uma relevante contribuição ao aprendizado de Química, que apresenta significativas dificuldades de compreensão dos conteúdos disciplinares.

Portanto, conclui-se que o uso dos laptops nas escolas tem proporcionado uma metodologia prática que favorece tanto o aluno como o professor ao lecionar as aulas. Desta forma o professor deve estar mais preparados para direcionar o programa com frequência aos alunos para o desempenho do aprendizado, trabalhando o ensino de química com didática utilizando os computadores como estratégicas educativa, social e cultural.

Finaliza-se enfatizando que o estímulo é importante na área de Ensino de Ciências, pois a integração de ensino deve estar presente à inclusão digital que leva em conta as diferenças contextuais e tecnológicas para o desenvolvimento da aprendizagem com uso de recursos computacionais em qualquer área da educação.

\section{Referências}

ARAGÃO, Rosália M. R. Teoria da aprendizagem significativa de David Ausubel. Campinas, São Paulo: Fac. de Educação - UNICAMP, Campinas, 1996.

BRASIL. Parâmetros curriculares nacionais: ensino médio. BRASÍLIA, MEC, 1998.

CNPq/Capes/SEED-MEC (2010) Edital no. 76/2010. PROUCA Fase 2. Disponível: <http://memoria.cnpq.br/editais/ct/2010/docs/076.pdf>. Acesso em: 02 out. 2013.

CRUZ, Renato. O que as empresas podem fazer pela inclusão digital. São Paulo: Instituto Ethos, 2004. Disponível em: 〈http://www.cdi.org.br/manual/inclusao.pdf>. Acesso em: 29 set. 2013.

DIAS, C. Usabilidade na WEB. Criando portais mais acessíveis. Rio de Janeiro: Alta Books, 2003.

GIL, A. C. Como elaborar projetos de pesquisa. São Paulo: Atlas, 2002. p.42 e 120.

LIBÂNEO, José C. Didática. - São Paulo: Cortez, 2008.

MENDES, Antonio da Silva Filho. "Inclusão Digital: Em Busca do Tempo Perdido". Disponível em: <http://www.espacoacademico.com.br/040/40amsf.htm>. Acesso em: 01 de nov. 2013.

MORAES, S.A. D. e Teruya, T. K. (2008). "Paulo Freire e a formação do professor na sociedade tecnológica." Disponível em: <http://www.nead.ufpr.br/conteudo/ artigos/paulo_freire.pdf>. Acesso em: 10 out. 2013.

RESNICK. M. (2001). Closing the Fluency Gap. Communications of the ACM, vol. 44, no.3. Disponível em: 〈http://llk.media.mit.edu/papers/mres-wef.pdf >. Acesso em: 02 set. 2013. 
V Congresso Brasileiro de Informática na Educação (CBIE 2016)

Anais dos Workshops do V Congresso Brasileiro de Informática na Educação (CBIE 2016)

STRUCHINER, Miriam; GIANNELLA, Tais R. Educação a Distância: reflexões para a prática nas universidades brasileiras. 1. ed. Brasília: Conselho de Reitores das Universidades Brasileiras, v. 1. 56 p. 2001.

TAVARES, N. R. B. História da Informática educacional no Brasil. Disponível em: <http://www.lapeq.fe.usp.br/textos/tics/pdf/neide.pdf>. Acesso em: 12 out. 2013.

WARSCHAUER, Mark. Reconceptualizing the digital divide. 2003. Disponível em: <http://www.firstmonday.dk/issues/issue7_7/warschauer/>. Acesso em: 16 out. 2013. 